Chronic Obstructive Pulmonary Diseases: Journal of the COPD Foundation。

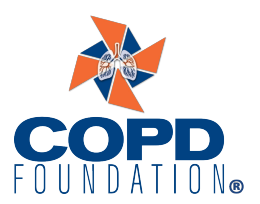

\author{
Original Research
}

\title{
Outcomes of Patients with COPD Hospitalized for Coronavirus Disease 2019
}

\author{
Daniel A. Puebla Neira, $\mathrm{MD}^{1}$ Abigail Watts, $\mathrm{MD}^{1}$ Justin Seashore, $\mathrm{MD}^{1}$ Alexander Duarte, $\mathrm{MD}^{1}$ Shawn P. Nishi, $\mathrm{MD}^{1}$ \\ Efstathia Polychronopoulou, MS, $\mathrm{MPH}^{2}$ Yong-Fang Kuo, $\mathrm{PhD}^{2,3}$ Jacques Baillargeon, $\mathrm{PhD}^{3}$ Gulshan Sharma, $\mathrm{MD}, \mathrm{MPH}^{1,3}$
}

\section{Abstract}

Rationale: There is controversy concerning the association of chronic obstructive pulmonary disease (COPD) as an independent risk factor for mortality in patients hospitalized with coronavirus disease 2019 (COVID-19). We hypothesize that patients with COPD hospitalized for COVID-19 have increased mortality risk.

Objective: To assess whether COPD increased the risk of mortality among patients hospitalized for COVID-19.

Methods: We conducted a retrospective cohort analysis of patients with COVID-19 between February 10 , 2020, and November 10, 2020, and hospitalized within 14 days of diagnosis. Electronic health records from U.S. facilities (Optum COVID-19 data) were used.

Results: In our cohort of 31,526 patients, 3030 (9.6\%) died during hospitalization. Mortality in patients with COPD was higher than that of patients without COPD, $14.02 \%$ and $8.8 \%$, respectively. Univariate (odds ratio [OR] 1.68; 95\% confidence interval [CI] 1.54 to 1.84) and multivariate (OR 1.33; 95\% CI 1.18 to 1.50) analysis showed that patients with COPD had greater odds of death due to COVID-19 than patients without COPD. We found significant interactions between COPD and sex and COPD and age. Specifically, the increased mortality risk associated with COPD was observed among female (OR 1.62; 95\% CI 1.36 to 1.95 ) but not male patients (OR 1.14; 95\% CI 0.97 to 1.34); and in patients aged 40 to 64 (OR 1.42 ; $95 \%$ CI 1.07 to 1.90 ) and 65 to 79 (OR 1.48 ; $95 \%$ CI 1.23 to 1.78 ) years.

Conclusions: COPD is an independent risk factor for death in adults aged 40 to 79 years hospitalized with COVID-19 infection.

\footnotetext{
Abbreviations: chronic obstructive pulmonary disease, COPD; coronavirus disease 2019, COVID-19; odds ratio, OR; confidence interval, CI, severe acute respiratory syndrome coronavirus 2, SARS-CoV-2; electronic health record, EHR; International Classification for Diseases, 1 Oth revision, Clinical Modification, ICD-10-CM; body mass index, BMI; chronic kidney disease, CKD; end-stage renal disease, ESRD; congestive heart failure, CHF; coronary artery disease, CAD; inhaled corticosteroid, ICS

Funding Support: Dr. Kuo reports grants from the University of Texas Medical Branch Claude D. Pepper Older Americans Independence Center and from the Agency of Healthcare Research and Quality during the conduct of the study.

Date of Acceptance: September 27, 2021 | Published Online Date: October 5, 2021

Citation: Puebla Neira DA, Watts A, Seashore J, et al. Outcomes of patients with COPD hospitalized for coronavirus disease 2019. Chronic Obstr Pulm Dis. 2021;8(4):517-527. doi: https://doi.org/10.15326/jcopdf.2021.0245
}

1 Division of Pulmonary, Critical Care and Sleep Medicine Department of Internal Medicine, University of Texas Medical Branch, Galveston, Texas, United States

2 Office of Biostatistics, University of Texas Medical Branch, Galveston, Texas, United States

3 Sealy Center on Aging, University of Texas Medical Branch, Galveston, Texas, United States

\section{Address correspondence to:}

Daniel A Puebla Neira, MD

301 University Blvd.

Galveston, TX 77555-0561

Email: puebla.daniel@me.com

Phone: 


\section{Keywords:}

chronic obstructive pulmonary disease; COPD; COVID-19; mortality

\section{Note: Some of the results of this study have been previously reported in the form of an abstract presented at the American Thoracic Society Conference 2021.}

\section{This article has an online supplement.}

\section{Introduction}

Severe acute respiratory syndrome coronavirus-2 (SARS-CoV-2) has caused, to date, 41 million cases and 667,244 deaths in the United States. ${ }^{1}$ Coronavirus disease 2019 (COVID-19), the infectious disease caused by SARS-CoV-2, has become the leading cause of death in the United States. ${ }^{2}$

Chronic obstructive pulmonary disease (COPD) is the fourth leading cause of death in the United States and affects 16 million Americans. ${ }^{3}$ During the COVID-19 pandemic, the association of COPD with adverse outcomes due to COVID-19 has been controversial. Worldwide, studies of patients with COVID-19 have reported COPD to be a risk factor for greater health care utilization, ${ }^{4}$ with increased risk of hospitalization, intensive care unit (ICU) admission, and death, ${ }^{5-12}$ while others have not shown this association. ${ }^{13-16}$ The association between COPD and adverse outcomes from COVID-19 remains disputed.

The prevalence of COPD among patients with COVID-19 varies $8,9,14,17,18$ between $1.5 \%$ and $18 \%$. This is likely an underestimation, as a SARS$\mathrm{CoV}-2$ infection can range in presentation from asymptomatic to severe disease. Severe COVID-19 may lead to hospitalization, ICU admission, noninvasive and invasive mechanical ventilation use, and death. ${ }^{19-24}$ Given the propensity for patients with COPD to suffer acute exacerbations induced by viral infections, such patients may be particularly vulnerable to adverse outcomes associated with COVID-19. ${ }^{25}$

The prevalence of COPD varies globally, ${ }^{26}$ therefore, the reported potential association of COPD as a risk factor for adverse outcomes in COVID-19 may vary by country or national health care system. Consequently, it is important to explore the characteristics and outcomes of patients hospitalized in the United States with COVID-19 and COPD. To evaluate COPD as an independent risk factor for mortality in patients with COVID-19, we conducted a large, nationally representative retrospective cohort study of U.S. patients hospitalized with COVID-19. We hypothesized that, among hospitalized patients with COVID-19, those with COPD would have an increased risk of inpatient mortality.

\section{Methods}

\section{Data Source}

In this retrospective cohort study, we used Optum's longitudinal COVID-19 electronic health record (EHR) database of more than 90 million patients across multiple hospital networks from all regions in the United States. The database contains deidentified inpatient and ambulatory encounter-level information, as well as procedure, prescription, and medication administration data. The University of Texas Medical Branch Institutional Review Board approved this study (IRB\# is 20-0180). Written informed consent was not required due to the deidentified nature of the patient data.

\section{Cohort}

The study cohort included patients diagnosed with COVID-19 between February 10, 2020, and November 10, 2020, who were hospitalized within 14 days of diagnosis. COVID-19 was identified by a positive laboratory test for SARS-CoV-2 or by the International Classification for Diseases, 10th revision, Clinical Modification (ICD-10-CM) diagnosis code U07.1 (See Table S1 in the online data supplement). Patients younger than 40 years at the time of diagnosis were excluded due to the low prevalence of COPD in this population ${ }^{27}$ (Figure S1 in the online data supplement).

\section{Variables}

The primary outcome was inpatient mortality among patients with COVID-19-associated hospitalization. The main independent variable of interest was COPD and was defined as having experienced $\geq 1$ inpatient or $\geq 2$ outpatient visits for COPD in the 1 year before the COVID-19 diagnosis (See Table S2 in the online data supplement).

We collected information on patient demographics 
as well as clinical and medication history. Comorbidities present before the COVID-19 diagnosis were identified using ICD-10-CM diagnosis codes. Convalescent plasma and medications administered during hospitalization (remdesivir, systemic corticosteroids) were identified from National Drug Codes or procedure codes. Inhaled corticosteroid use was defined as having at least 1 prescription in the 12 months preceding the COVID-19 diagnosis. For body mass index (BMI) and insurance status, when multiple observations were available, we recorded the value at the date closest to the COVID-19 diagnosis.

\section{Statistical Analysis}

Patient and clinical characteristics were summarized as frequencies and percentages or meanststandard deviations and compared with chi-square statistics or $t$-tests as appropriate. To determine the effect of COPD on inpatient mortality, we fit a logistic regression model with COPD as the primary predictor, adjusted for covariates. We tested a priori interactions between COPD and sex, COPD and age, COPD and race, and COPD and inhaled corticosteroids. For significant interaction terms, we stratified our cohort in subgroups and examined the effect of COPD on inpatient mortality within each stratum with separate multivariate models. All analyses were performed with SAS 9.4 (SAS, Inc., Cary, North Carolina).

\section{Results}

\section{Demographics and Patient Characteristics}

During the study period, 31,526 patients hospitalized with COVID-19 were identified and baseline characteristics of the cohort are presented in Table 1. Patients with COPD comprised $15.09 \%$ of the cohort (4758 patients), which consisted of mostly White (68.6\%) males (52.1\%) with a BMI<30 kg/m² $(46 \%)$ and mean age of $72 \pm 11.2$ years. A greater percentage of patients with COPD were admitted to the ICU (COPD 28.8\% versus non-COPD 22.2\%, $p<0.0001)$ and received mechanical ventilation (COPD 20.2\% versus non-COPD 13.8\%, $p<0.0001$ ), systemic steroids (COPD $56.3 \%$ versus non-COPD $43.7 \%, p<0.0001$ ), convalescent plasma (COPD 4.5\% versus non-COPD 3.7\%, $p=0.0053$ ), and remdesivir (COPD $12.9 \%$ versus non-COPD $11.5 \%, p=0.0051$ ).
Similarly, a greater percentage of patients with COPD received a palliative care consultation (COPD 20.3\% versus non-COPD 14.3\%, $p<0.0001$ ) (Table 2). In addition, more patients with COPD were discharged to a non-home setting compared to patients without COPD. In patients with COPD, the most common non-home setting discharge destination was a skilled nursing facility (18.2\%), followed by hospice (4.6\%) (Table S3 in the online data supplement).

\section{Effect of COPD on COVID-19 Inpatient Mortality}

Overall hospital mortality was 9.61\% for hospitalized patients with COVID-19. Mortality was significantly higher in patients with COPD than in patients without COPD, $14.02 \%$ and $8.83 \%$, respectively, $p<0.0001$ (Table 2). In univariate analysis, patients with COPD had $68 \%$ greater odds of death due to COVID-19 than patients without COPD (odds ratio [OR] 1.68; 95\% confidence interval [CI] 1.54 to 1.84). After adjusting for clinical and demographic factors, we observed a modest reduction in the odds of mortality in patents with COVID-19 and COPD (OR 1.33; 95\% CI 1.18 to 1.50) (See Table 3). We found significant interactions between COPD and sex and COPD and age, but not between COPD and race or COPD and inhaled corticosteroid (ICS) use. Specifically, the increased mortality risk associated with COPD was observed among female (OR 1.62; 95\% CI 1.36 to 1.95 ) but not male patients (OR 1.14; 95\% CI 0.97 -to 1.34); and in patients aged 40 to 64 (OR 1.42; 95\% CI 1.07 to 1.90 ) and 65 to 79 (OR 1.48; $95 \%$ CI 1.23 to 1.78 ) years, but not in patients aged 80 years or older (OR 1.17 ; $95 \%$ CI 0.97 to 1.42 ) (Figure 1).

\section{Discussion}

In this large, nationally representative U.S. cohort study, we found that COPD was an independent risk factor for inpatient mortality in patients hospitalized with COVID-19. This association was primarily driven by the effect in women and in adults between 40 and 79 years of age. This association persisted after adjustment for a wide range of potentially confounding variables, including age, race, medications received during hospitalization (remdesivir, systemic steroids), BMI, comorbidities, and use of mechanical ventilation. 


\section{Figure 1. Interaction Effects Examined in the Multivariate Model Showing the Association Between COPD and Mortality by Sex ${ }^{a}$ and Mortality by Age $^{b}$ and Adjusted for All Other Covariates in Patients Hospitalized with COVID-19c}

Panel A

Odds Ratio of Inpatient Mortality

from COVID-19

for COPD vs non-COPD by Sex

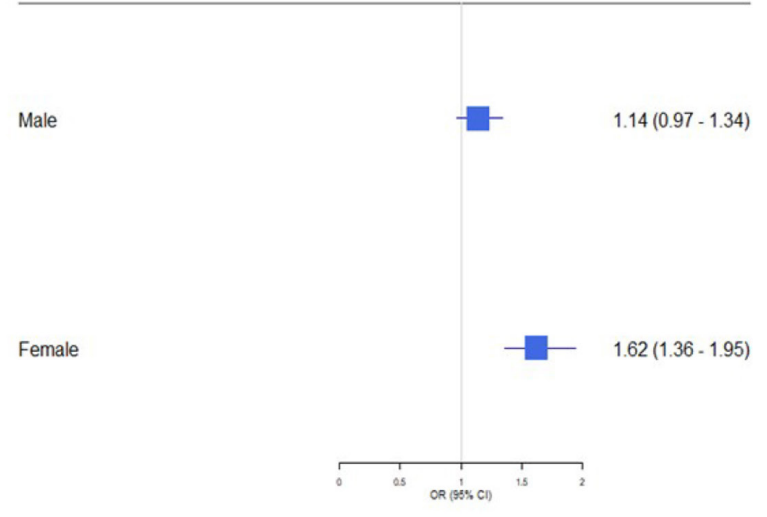

Panel B

\author{
Odds Ratio of Inpatient Mortality \\ from COVID-19 for COPD vs
}

non-COPD by Age Groups

OR $(95 \% \mathrm{Cl})$

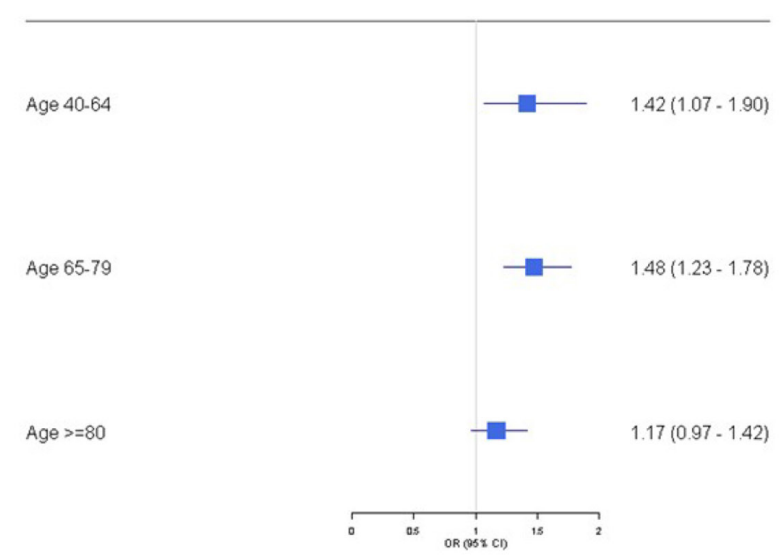

apanel A
bPanel B
Cin the United States

The results of the interaction effects showed that the association between COPD and mortality varied significantly by sex $(p<0.0001)$ and age $(p=0.014)$, but not race $(p=0.323)$ or ICS use $(p=0.725)$ (data not shown).

COPD=chronic obstructive pulmonary disease; COVID-19=coronavirus disease 2019; ICS= inhaled corticosteroid; OR=odds ratio; $C I=$ confidence interval

Interestingly, all patients with COVID-19 and COPD had higher rates of ICU admission, mechanical ventilation, and palliative care consultation than those without COPD. Our results of worse outcomes amongst COVID-19 patients with COPD are consistent with previous research. ${ }^{5-12}$

Our finding of worse mortality risk in women with COPD who were hospitalized due to COVID-19 is contrary to the overall outcomes of women with COVID-19 without COPD. ${ }^{9,12,13,28}$ Why do women with COVID-19 who have COPD have increased risk of mortality? Prior to the COVID-19 pandemic, we knew that women with COPD have worse symptoms and airflow limitation compared to men, despite lower pack years of smoking. ${ }^{29}$ Also, women's COPD-related hospitalizations and deaths in the United States are worse compared to those of men. ${ }^{30,31}$ In addition, women's smaller lung size and other sex-specific factors may explain the observed association of worse mortality in women with COPD and COVID-19 compared to men. ${ }^{32}$
For example, estrogen has been reported to have an anti-inflammatory effect in pre-menopausal women ${ }^{33,34}$ as well as against coronaviruses. ${ }^{35}$ It is likely that the protective effect observed among women with COVID-19 has been driven primarily by pre-menopausal women. ${ }^{33}$ Most women with COPD are post-menopausal ${ }^{27}$ and likely have lost the protective effect of estrogen. ${ }^{30-32}$

In addition to the interaction between sex and COPD, we found that patients with COPD who are 40 to 79 years old are at increased risk of death due to COVID-19, but those 80 years and older are not. Patients who are $\geq 80$ years old have likely accumulated several comorbidities that may impair their health at baseline and ours (see Table 3) and other's studies have consistently shown that older age and comorbidities are associated with worse outcomes from COVID-19. ${ }^{11,15,23,28,36}$ Very likely, these 2 variables have concealed any association between COPD and mortality from COVID-19 in this age group ( $\geq 80$ years old). On the other hand, 
Table 1. Characteristics of Patients With and Without COPD and Hospitalized Due to COVID-19a

\begin{tabular}{|c|c|c|c|c|c|}
\hline Characteristics & Category & Total $^{b}$ & $\begin{array}{l}\text { Patients with COPD } \\
\qquad N=4758 \mathrm{~N}(\%)\end{array}$ & $\begin{array}{l}\text { Patients without COPD } \\
\qquad \mathrm{N}=26,768 \mathrm{~N}(\%)\end{array}$ & $p$-value \\
\hline Age, mean (SD) & & 31,526 & $72.0( \pm 11.2)$ & $65.2( \pm 13.7)$ & $<0.0001$ \\
\hline \multirow{3}{*}{ Age } & $40-64$ & 14,562 & 1243 (26.1) & $13,319(49.8)$ & \multirow{3}{*}{$<0.0001$} \\
\hline & $65-79$ & 10,775 & 2171 (45.6) & $8604(32.1)$ & \\
\hline & $\geq 80$ & 6189 & $1344(28.3)$ & $4845(18.1)$ & \\
\hline \multirow{2}{*}{ Gender } & Female & 14,703 & 2277 (47.9) & $12,426(46.4)$ & \multirow[t]{3}{*}{0.0675} \\
\hline & Male & 16,823 & 2481 (52.1) & 14,342 (53.6) & \\
\hline \multirow[t]{5}{*}{ Race/Ethnicityd } & White & 17,037 & $3265(68.6)$ & $13,772(51.5)$ & \\
\hline & Black & 6168 & $895(18.8)$ & $5273(19.7)$ & \multirow[t]{4}{*}{$<.0001$} \\
\hline & Asian & 774 & $51(1.1)$ & $723(2.7)$ & \\
\hline & Hispanic $^{\mathrm{e}}$ & 4139 & $250(5.3)$ & $3889(14.5)$ & \\
\hline & Other/Unknown & 3408 & $297(6.2)$ & $3111(11.6)$ & \\
\hline BMI, mean $\mathrm{Kg} / \mathrm{m}^{2}$ (SD) & & 23,450 & $30.5(8.9)$ & $31.3(8.0)$ & $<0.0001$ \\
\hline \multirow[t]{3}{*}{ BMI } & $<30 \mathrm{Kg} / \mathrm{m}^{2}$ & 11,808 & $2190(46.0)$ & $9618(35.9)$ & \multirow[t]{3}{*}{$<0.0001$} \\
\hline & $\geq 30 \mathrm{Kg} / \mathrm{m}^{2}$ & 11,642 & $1840(38.7)$ & $9802(36.6)$ & \\
\hline & Unknown & 8076 & $728(15.3)$ & $7348(27.5)$ & \\
\hline \multirow[t]{5}{*}{ Census Bureau Region } & Midwest & 12,275 & $2043(42.9)$ & $10,232(38.2)$ & \multirow[t]{5}{*}{$<0.0001$} \\
\hline & Northeast & 9102 & $1095(23.0)$ & 8007 (29.9) & \\
\hline & South & 6872 & $1134(23.8)$ & $5738(21.4)$ & \\
\hline & West & 2349 & $319(6.7)$ & $2030(7.6)$ & \\
\hline & Other/Unknown & 928 & 167 (3.5) & $761(2.8)$ & \\
\hline \multirow[t]{4}{*}{ Insurance Status } & Commercial & 9663 & 756 (15.9) & 8907 (33.3) & \multirow[t]{4}{*}{$<0.0001$} \\
\hline & Medicaid & 3325 & $461(9.7)$ & $2864(10.7)$ & \\
\hline & Medicare & 15,876 & $3429(72.1)$ & $12,447(46.5)$ & \\
\hline & Unknown/Other & 2662 & $112(2.4)$ & $2550(9.5)$ & \\
\hline \multirow[t]{2}{*}{ Diabetes Mellitus } & Yes & 9725 & $1829(38.44)$ & 7896 (29.5) & \multirow[t]{2}{*}{$<0.0001$} \\
\hline & No & 21,801 & 2929 (61.56) & $18,872(70.5)$ & \\
\hline \multirow[t]{2}{*}{ Hypertension } & Yes & 19,155 & $3718(78.14)$ & 15,437 (57.67) & \multirow[t]{2}{*}{$<0.0001$} \\
\hline & No & 12,371 & $1040(21.86)$ & $11,331(42.33)$ & \\
\hline \multirow[t]{2}{*}{ Asthma } & Yes & 3651 & $1084(22.78)$ & 2567 (9.59) & \multirow[t]{2}{*}{$<0.0001$} \\
\hline & No & 27,875 & $3674(77.22)$ & $24,201(90.41)$ & \\
\hline \multirow[t]{2}{*}{ CKD } & Yes & 3908 & $1010(21.23)$ & $2898(10.83)$ & \multirow[t]{2}{*}{$<0.0001$} \\
\hline & No & 27,618 & $3748(78.77)$ & $23870(89.17)$ & \\
\hline \multirow[t]{2}{*}{ ESRD } & Yes & 1043 & $205(4.31)$ & $838(3.13)$ & \multirow[t]{2}{*}{$<0.0001$} \\
\hline & No & 30,483 & $4553(95.69)$ & 25930 (96.87) & \\
\hline \multirow[t]{2}{*}{ Stroke } & Yes & 9308 & $1507(31.67)$ & 7801 (29.14) & \multirow[t]{2}{*}{0.0004} \\
\hline & No & 22,218 & $3251(68.33)$ & 18967 (70.86) & \\
\hline CHF & Yes & 5496 & $1833(38.52)$ & $3663(13.68)$ & $<0.0001$ \\
\hline & No & 26,030 & 2925 (61.48) & 23,105 (86.32) & \\
\hline Cancer & Yes & 777 & $202(4.25)$ & $575(2.15)$ & $<0.0001$ \\
\hline & No & 30,749 & 4556 (95.75) & $26,193(97.85)$ & \\
\hline CAD & Yes & 6453 & $1951(41)$ & $4502(16.82)$ & $<0.0001$ \\
\hline & No & 25,073 & 2807 (59) & $22266(83.18)$ & \\
\hline Liver Disease & Yes & 2787 & 608 (12.78) & $2179(8.14)$ & $<0.0001$ \\
\hline & No & 28,739 & $4150(87.22)$ & 24589 (91.86) & \\
\hline
\end{tabular}

${ }^{a}$ Between February 10, 2020, and November 10, 2020, in the United States

${ }^{b}$ Our cohort was obtained from Optum's COVID-19 database, which includes EHR data for more than 90 million patients across multiple hospital networks from all regions in the United States. Cohort included patients who were diagnosed with COVID-19 between February 10 , 
2020, and November 10, 2020, and were hospitalized within 14 days from diagnosis. COVID-19 was identified by a positive laboratory test for SARS-CoV-2 or by ICD-10-CM diagnosis code U07.1 Prior to enrollment patients needed to have had received care in Optum's healthcare network at least once in the 12 months before COVID-19 diagnosis.

${ }^{c}$ Presence of COPD was defined as having at least 1 inpatient or 2 outpatient diagnoses in the 1 year before COVID-19 diagnosis (See Table $\mathrm{S} 2$ in the online data supplement).

dPersons self-identifying as non-Hispanic ethnicity, where categorized based on race (White, Black, Asian, Other/Unknown).

"Patients self-identifying as Hispanic ethnicity, were included in the "Hispanic" group, regardless of race.

$\mathrm{COPD}=$ chronic obstructive pulmonary disease; COVID-19=coronavirus disease 2019; $\mathrm{SD}=\mathrm{standard}$ deviation; BMI=body mass index; $\mathrm{CKD}=$ chronic kidney disease; $\mathrm{ESRD}=$ end stage renal disease; $\mathrm{CHF}=$ congestive heart failure; $\mathrm{CAD}=\mathrm{coronary}$ artery disease; $\mathrm{EHR}=\mathrm{electronic}$ health record; SARS-CoV-2=severe acute respiratory syndrome coronavirus-2; ICD-10-CM=International Classification of Diseases, 10th revision, Clinical Modification.

\section{Table 2. Process of Care and Outcomes of Patients With and Without COPD Hospitalized Due to} COVID-19a

\begin{tabular}{|c|c|c|c|c|c|}
\hline Characteristics & Category & Total ${ }^{b}$ & $\begin{array}{l}\text { Patients with COPD } \\
\quad \mathrm{N}=4758^{\circ} \mathrm{N}(\%)\end{array}$ & $\begin{array}{l}\text { Patients without COPD } \\
\qquad \mathrm{N}=26,768 \mathrm{~N}(\%)\end{array}$ & $p$-value \\
\hline \multirow[t]{2}{*}{ Mechanical Ventilation } & Yes & 4659 & $959(20.2)$ & $3700(13.8)$ & \multirow[t]{2}{*}{$<0.0001$} \\
\hline & No & 26,867 & 3799 (79.8) & 23,068 (86.2) & \\
\hline \multirow[t]{2}{*}{ ICS $^{\mathbf{d}}$} & Yes & 4794 & $2596(54.6)$ & $2198(8.2)$ & \multirow[t]{2}{*}{$<0.0001$} \\
\hline & No & 26,732 & $2162(45.4)$ & $24,570(91.8)$ & \\
\hline \multirow[t]{2}{*}{ Systemic Steroids ${ }^{e}$} & Yes & 14,360 & $2677(56.3)$ & $11,683(43.7)$ & \multirow[t]{2}{*}{$<0.0001$} \\
\hline & No & 17,166 & $2081(43.7)$ & 15,085 (56.4) & \\
\hline \multirow[t]{2}{*}{ Remdesivirf $^{\mathrm{f}}$} & Yes & 3702 & $616(12.9)$ & $3086(11.5)$ & \multirow[t]{2}{*}{0.0051} \\
\hline & No & 27,824 & $4142(87.1)$ & $23,682(88.5)$ & \\
\hline \multirow[t]{2}{*}{ Convalescent Plasma Therapy ${ }^{e}$} & Yes & 1206 & $216(4.5)$ & $990(3.7)$ & \multirow[t]{2}{*}{0.0053} \\
\hline & No & 30,320 & 4542 (95.5) & 25,778 (96.3) & \\
\hline \multirow[t]{2}{*}{ Palliative Care Consultation } & Yes & 4779 & $964(20.3)$ & $3815(14.3)$ & \multirow[t]{2}{*}{$<0.0001$} \\
\hline & No & 26,747 & $3794(79.7)$ & $22,953(85.8)$ & \\
\hline Length of Stayf ${ }^{\text {Mean }}$ (SD) & & & $9.8(9.9)$ & $8.5(10.1)$ & $<0.0001$ \\
\hline \multirow[t]{2}{*}{ Inpatient Death } & Yes & 3030 & $667(14.0)$ & $2363(8.8)$ & \multirow[t]{2}{*}{$<0.0001$} \\
\hline & No & 28,496 & $4091(86.0)$ & 24,405 (91.2) & \\
\hline
\end{tabular}

${ }^{a}$ Between February 10, 2020, and November 10, 2020, in the United States

${ }^{\mathrm{b}}$ COVID-19 was identified by a positive laboratory test for SARS-CoV-2 or by ICD-10-CM diagnosis code U07.1

${ }^{c}$ Presence of COPD was defined as having at least 1 inpatient or 2 outpatient diagnoses in the 1 year before COVID-19 diagnosis (See Table S2 in the online data supplement).

$\mathrm{d}_{\text {ICS }}$ prescription obtained within a year of COVID-19 diagnosis.

${ }^{\mathrm{e}}$ Convalescent plasma and medications administered during hospitalization (remdesivir, systemic steroids) were identified from National Drug Codes or procedure codes.

${ }_{\mathrm{f}}$ Length of stay as measured in days.

$\mathrm{COPD}=$ chronic obstructive pulmonary disease; COVID-19=coronavirus disease 2019; ICS=inhaled corticosteroid; SD=standard deviation; SARS-CoV-2=severe acute respiratory syndrome coronavirus-2; ICD-10-CM=International Classification of Diseases, 10 th revision,

Clinical Modification

of particular concern is our finding of a $42 \%$ higher likelihood of death from COVID-19 in younger patients with COPD, those aged 40 to 64 years. These patients may have developed "early COPD" and possibly were exposed to significant smoking and other risk factors earlier in life that led to the development of likely anatomical, immunologic, and physiologic abnormalities ${ }^{37}$ that may have made them more susceptible to die from COVID-19.

Although the interaction between COPD and ICS use on COVID-19 mortality in our cohort was non-significant, we did find that a history of an ICS prescription was associated with a lower risk of death in all hospitalized patients due to COVID-19. Despite this provocative finding, we do not know whether the ICS prescription had been filled. Use of an ICS was assumed if patients had a history of an ICS prescription 1 year prior to the COVID diagnosis or if the patient reported use. Furthermore, a recent United Kingdom-based observational study did not provide definitive answers to explain this association $^{38}$ and more studies would be necessary to further characterize this finding.

It is unclear what mechanisms drive the worse outcomes seen in patients with COPD hospitalized with COVID-19, but several biological factors have 


\section{Table 3. Multivariate Logistic Regression Model of the Effect of COPD on COVID-19-related Mortality in Patients Hospitalized Due to COVID-19a}

\begin{tabular}{|c|c|c|c|}
\hline Variables & & Odds Ratio (95\% Cl) & $P$ value \\
\hline COPDb & Yes vs No & $1.33(1.18-1.50)$ & $<0.0001$ \\
\hline \multirow[t]{2}{*}{ Age } & $65-79$ vs $40-64$ & $2.44(2.19-2.71)$ & $<0.0001$ \\
\hline & $\geq 80$ vs $40-64$ & $5.74(5.09-6.49)$ & $<0.0001$ \\
\hline Gender & Male vs Female & $1.22(1.12-1.33)$ & $<0.0001$ \\
\hline \multirow[t]{4}{*}{ Race/Ethnicityc } & Black vs White & $1.11(0.99-1.25)$ & 0.0813 \\
\hline & Asian vs White & $1.31(1.03-1.68)$ & 0.0293 \\
\hline & Hispanic vs White & $1.29(1.13-1.48)$ & 0.0002 \\
\hline & Other/Unknown vs White & $1.35(1.18-1.54)$ & $<0.0001$ \\
\hline \multirow[t]{2}{*}{ BMId $^{d}$} & $\geq 30 \mathrm{Kg} / \mathrm{m}^{2} \mathrm{vs}<30 \mathrm{Kg} / \mathrm{m}^{2}$ & $0.96(0.86-1.06)$ & 0.3956 \\
\hline & Unknown vs $<30 \mathrm{Kg} / \mathrm{m}^{2}$ & $1.41(1.27-1.57)$ & $<0.0001$ \\
\hline Diabetes & Yes vs No & $1.02(0.92-1.121)$ & 0.7463 \\
\hline Hypertension & Yes vs No & $0.94(0.84-1.04)$ & 0.2394 \\
\hline Asthma & Yes vs No & $1.01(0.88-1.17)$ & 0.8503 \\
\hline CKD & Yes vs No & $1.27(1.11-1.45)$ & 0.0004 \\
\hline ESRD & Yes vs No & $1.24(0.99-1.56)$ & 0.0603 \\
\hline STROKE & Yes vs No & $1.12(1.01-1.21)$ & 0.0286 \\
\hline CHF & Yes vs No & $1.09(0.97-1.23)$ & 0.1342 \\
\hline Cancer & Yes vs No & $1.12(0.87-1.44)$ & 0.3811 \\
\hline CAD & Yes vs No & $1.15(1.03-1.28)$ & 0.0142 \\
\hline Liver Disease & Yes vs No & $1.10(0.95-1.28)$ & 0.1885 \\
\hline Systemic Steroids ${ }^{\mathbf{e}}$ & Yes vs No & $1.07(0.98-1.17)$ & 0.1394 \\
\hline Remdesivire & Yes vs No & $1.54(1.35-1.75)$ & $<0.0001$ \\
\hline Convalescent Plasma & Yes vs No & $1.02(0.83-1.24)$ & 0.8873 \\
\hline ICS $^{\mathbf{f}}$ & Yes vs No & $0.73(0.64-0.84)$ & $<0.0001$ \\
\hline Mechanical Ventilation & Yes vs No & $9.27(8.42-10.20)$ & $<0.0001$ \\
\hline Length of Stayg & - & $1.01(1.00-1.01)$ & 0.0074 \\
\hline
\end{tabular}

${ }^{a}$ Between February 10, 2020, and November 10, 2020, in the United States.

${ }^{b}$ Presence of COPD was defined as having at least 1 inpatient or 2 outpatient diagnoses in the 1 year before COVID diagnosis (Table S2 in the online supplement).

${ }^{\mathrm{c}}$ Persons self-identifying as non-Hispanic ethnicity, were categorized based on race (White, Black, Asian, Other/Unknown). Patients self-identifying as Hispanic ethnicity, were included in the "Hispanic" group, regardless of race.

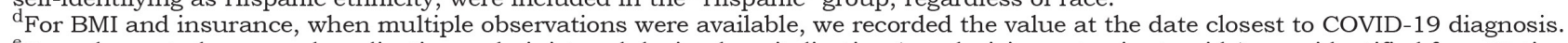
${ }^{e}$ Convalescent plasma and medications administered during hospitalization (remdesivir, systemic steroids) were identified from National Drug Codes or procedure codes.

f ICS use was evaluated by having at least one prescription in the 12 months preceding COVID-19 diagnosis.

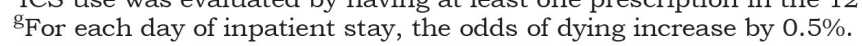

$\mathrm{COPD}=$ chronic obstructive pulmonary disease; COVID-19=coronavirus disease 2019; CI=confidence interval; BMI=body mass index; $\mathrm{CKD}=$ chronic kidney disease; $\mathrm{ESRD}=$ end stage renal disease; $\mathrm{CHF}=$ congestive heart failure; $\mathrm{CAD}=\mathrm{coronary}$ artery disease;

ICS $=$ inhaled corticosteroids

been proposed, including chronic lung inflammation, oxidative stress, protease-antiprotease imbalance, and increased airway mediators. ${ }^{6,39,40}$ Additionally, patients with COPD have increased levels of angiotensin-converting enzyme 2 , the receptor used by SARS-CoV-2 to enter host cells, that may enhance viral pathogenicity. ${ }^{41-44}$ Moreover, viral infections can contribute to COPD exacerbations, leading to hospitalization, and acute exacerbations of COPD has been associated with poor outcomes ${ }^{45}$
It is unknown whether patients with COPD have a higher risk of acquiring the SARS-CoV-2 infection. Studies based in the United Kingdom, Europe, and Asia report a varied prevalence of patients with COPD amongst hospitalized patients with COVID-19, ${ }^{9,18,40}$ and COPD has been shown to be a risk factor for hospitalization due to COVID-19. ${ }^{15}$ The association between COPD, severe COVID-19, and mortality related to COVID-19 varies. ${ }^{9-13,15,46}$ The current study represents the largest cohort 
studied to date of patients with COPD who have been hospitalized due to COVID-19 in the United States. Similarly, our findings of increased mortality associated with COPD support previous reports of poor outcomes in COVID-19 patients with chronic respiratory conditions. For example, patients with interstitial lung disease and COVID-19 were more likely to be hospitalized, require ICU care, and die compared to patients with COVID-19 without interstitial lung disease. ${ }^{47,48}$

We acknowledge that this study has limitations, including its retrospective nature. The results merely show an association between COPD and mortality in hospitalized patients with COVID-19. Since we used ICD-10-CM codes to identify COPD, it is possible that our population may over- or under-represent the true prevalence of COPD in the general population. ${ }^{49}$ In addition, we were not able to assess when remdesivir and systemic steroids were administered in relation to a patient's hospitalization, the selection criteria used for drug prescription, or the duration of COVID-19 illness prior to the hospital admission. These unmeasured variables may have influenced whether the use of remdesivir and systemic corticosteroids affected clinical outcomes in hospitalized patients with COVID-19. Finally, patients with COPD have significant comorbid conditions, ${ }^{50}$ and these may have mediated the association between COPD and increased hospital mortality. Yet, after adjustment for demographic and clinical factors, our findings indicated that COPD was an independent factor for mortality in patients hospitalized with COVID-19.

In conclusion, COPD is an independent risk factor for death in adults aged 40 to 79 years hospitalized due to COVID-19.

\section{Acknowledgements Author contributions:}

All authors have contributed to the current manuscript in the following manner:

- Substantial contribution to the conception, design, data acquisition, analysis and interpretation of the manuscript.

- Drafted and/or revised the manuscript for important intellectual content.

- Approved the final version to be submitted for publication.

- Agreed to be accountable for all aspects of the work and have ensured that questions related to the accuracy and integrity of any part of the manuscript are appropriately investigated and resolved.

The authors acknowledge and greatly appreciate the assistance in the preparation of this manuscript by: En Shuo Hsu, MA (Office of Biostatistics, University of Texas Medical Branch, Galveston, Texas); Sarah Toombs Smith, PhD, ELS (Research Communications Manager and Fellow, Sealy Center on Aging, University of Texas Medical Branch, Galveston, Texas); Tara N. Atkins, MLIS (Reference Librarian Moody Medical Library/Academic Resources, University of Texas Medical Branch, Galveston, Texas).

\section{Declaration of interest}

Drs. Puebla Neira, Watts, Seashore, Duarte, Nishi, Baillargeon and Sharma, along with Ms. Polychronopoulou, have nothing to disclose. Dr. Kuo reports grants from the UTMB Claude D. Pepper Older Americans Independence Center and from the Agency of Healthcare Research and Quality during the conduct of the study. 


\section{References}

1. 1. World Health Organization (WHO). WHO coronavirus (COVID-19) dashboard. WHO website. Published 2020. Accessed September 20, 2021. https://covid19.who.int/

2. Woolf SH, Chapman DA, Lee JH. COVID-19 as the leading cause of death in the United States. JAMA. 2021;325(2):123-124. doi: https://doi.org/10.1001/jama.2020.24865

3. Centers for Disease Control and Prevention (CDC). Chronic obstructive pulmonary disease (COPD) Includes: chronic bronchitis and emphysema. CDC website. Updated September 13, 2021. Accessed August 31, 2021. https://www.cdc.gov/nchs/fastats/copd.htm

4. Attaway A, Zein J, Hatipoğlu U. SARS-CoV-2 infection in the COPD population is associated with increased healthcare utilization: an analysis of Cleveland Clinic's COVID-19 registry. EClinicalMedicine. 2020;26:100515.

doi: https://doi.org/10.1016/j.eclinm.2020.100515

5. Gerayeli FV, Milne S, Cheung C, et al. COPD and the risk of poor outcomes in COVID-19: a systematic review and meta-analysis. EClinicalMedicine. 2021;33:100789.

doi: https://doi.org/10.1016/j.eclinm.2021.100789

6. Zhao Q, Meng M, Kumar R, et al. The impact of COPD and smoking history on the severity of COVID-19: a systemic review and metaanalysis. JMed Virol. 2020;92(10):1915-1921. doi: https://doi.org/10.1002/jmv.25889

7. Guan W, Ni Z, Hu Y, et al. Clinical characteristics of coronavirus disease 2019 in China. N Engl J Med. 2020;382(18):1708-1720. doi: https://doi.org/10.1056/NEJMoa2002032

8. Feng Y, Ling Y, Bai T, et al. COVID-19 with different severities: a multicenter study of clinical features. Am J Respir Crit Care Med. 2020;201(11):1380-1388.

doi: https://doi.org/10.1164/rccm.202002-0445OC

9. Docherty AB, Harrison EM, Green CA, et al. Features of 20133 UK patients in hospital with COVID-19 using the ISARIC WHO Clinical Characterisation Protocol: prospective observational cohort study. BMJ. 2020;369:1-12. doi: https://doi.org/10.1136/bmj.m1985

10. Lippi G, Henry BM. Chronic obstructive pulmonary disease is associated with severe coronavirus disease 2019 (COVID-19): COPD and COVID-19. Respir Med. 2020;167:105941. doi: https://doi.org/10.1016/j.rmed.2020.105941

11. Singh AK, Gillies CL, Singh R, et al. Prevalence of co-morbidities and their association with mortality in patients with COVID-19: a systematic review and meta-analysis. Diabetes Obes Metab. 2020;22(10):1915-1924. doi: https://doi.org/10.1111/dom.14124

12. Grasselli G, Greco M, Zanella A, et al. risk factors associated with mortality among patients with COVID-19 in intensive care units in Lombardy, Italy. JAMA Intern Med. 2020;180(10):1345-1355. doi: https://doi.org/10.1001/jamainternmed.2020.3539
13. Petrilli CM, Jones SA, Yang J, et al. Factors associated with hospital admission and critical illness among 5279 people with coronavirus disease 2019 in New York City: prospective cohort study. BMJ. 2020;369:m1966. doi: https://doi.org/10.1136/bmj.m1966

14. Zhou F, Yu T, Du R, et al. Clinical course and risk factors for mortality of adult inpatients with COVID-19 in Wuhan, China: a retrospective cohort study. Lancet. 2020;395(10229):1054-1062. doi: https://doi.org/10.1016/S0140-6736(20)30566-3

15. Hippisley-Cox J, Young D, Coupland C, et al. Risk of severe COVID-19 disease with $\mathrm{ACE}$ inhibitors and angiotensin receptor blockers: cohort study including 8.3 million people. Heart. 2020;106(19):1503-1511. doi: https://doi.org/10.1136/heartjnl-2020-317393

16. Marron RM, Zheng M, Fernandez Romero G, et al. Impact of chronic obstructive pulmonary disease and emphysema on outcomes of hospitalized patients with COVID-19 pneumonia. Chronic Obstr Pulm Dis. 2021;8(2):255-268.

doi: https://doi.org/10.15326/jcopdf.2020.0200

17. Williamson EJ, Walker AJ, Bhaskaran K, et al. Factors associated with COVID-19-related death using OpenSAFELY. Nature. 2020;584(7821):430-436.

doi: https://doi.org/10.1038/s41586-020-2521-4

18. Halpin DMG, Faner R, Sibila O, Badia JR, Agusti A. Do chronic respiratory diseases or their treatment affect the risk of SARS-CoV-2 infection? Lancet Respir Med. 2020;8(5):436-438. doi: https://doi.org/10.1016/S2213-2600(20)30167-3

19. McElvaney OJ, McEvoy NL, McElvaney OF, et al. Characterization of the inflammatory response to severe COVID-19 Illness. Am J Respir Crit Care Med. 2020;202(6):812-821.

doi: https://doi.org/10.1164/rccm.202005-15830C

20. Salje H, Kiem CT, Lefrancq N, et al. Estimating the burden of SARSCoV-2 in France. Science. 2020;369(6500):208-211. doi: https://doi.org/10.1126/science.abc3517

21. Lavezzo E, Franchin E, Ciavarella C, et al. Suppression of a SARS-CoV-2 outbreak in the Italian municipality of Vo'. Nature. 2020;584(7821):425-429.

doi: https://doi.org/10.1038/s41586-020-2488-1

22. Verity R, Okell LC, Dorigatti I, et al. Estimates of the severity of coronavirus disease 2019: a model-based analysis. Lancet Infect Dis. 2020;20(6):669-677.

doi: https://doi.org/10.1016/S1473-3099(20)30243-7

23. Emami A, Javamardi F, PirbonyehN, AkbariA. Prevalence ofunderlying diseases in hospitalized patients with COVID-19: a systematic review and meta-analysis. Arch Acad Emerg Med. 2020;8(1):e35. doi: https://doi.org/10.22037/aaem.v8i1.600

24. Centers for Disease Control and Prevention (CDC). COVID data tracker. Updated October 6, 2021. Accessed September 20, 2021. https://covid.cdc.gov/covid-data-tracker/\#datatracker-home 
25. Halpin DMG, Criner GJ, Papi A, et al. Global initiative for the diagnosis, management, and prevention of chronic obstructive lung disease: the 2020 GOLD science committee report on COVID-19 and COPD. Am J Respir Crit Care Med. 2021;203(1):24-36.

doi: https://doi.org/10.1164/rccm.202009-3533SO

26. Ho T, Cusack RP, Chaudhary N, Satia I, Kurmi OP. Under- and overdiagnosis of COPD: a global perspective. Breathe (Sheff). 2019;15(1):2435. doi: https://doi.org/10.1183/20734735.0346-2018

27. Akinbami L, Liu X. Chronic obstructive pulmonary disease among adults aged 18 and over in the United States, 1998-2009. NCHS Data Brief. 2011;(63):1-8. https://pubmed.ncbi.nlm.nih.gov/22142836/

28. Puebla Neira DA, Watts A, Seashore J, Polychronopoulou E, Kuo Y-F, Sharma G. Smoking and risk of COVID-19 hospitalization. Respir Med. 2021;182:106414.

doi: https://doi.org/10.1016/j.rmed.2021.106414

29. DeMeo DL, Ramagopalan S, Kavati A, et al. Women manifest more severe COPD symptoms across the life course. Int J Chron Obstruct Pulmon Dis. 2018;13:3021-3029.

doi: https://doi.org/10.2147/COPD.S160270

30. Jenkins CR, Chapman KR, Donohue JF, Roche N, Tsiligianni I, Han MLK. Improving the management of COPD in women. Chest. 2017;151(3):686-696.

doi: https://doi.org/10.1016/j.chest.2016.10.031

31. Celli B, Vestbo J, Jenkins CR, et al. Sex differences in mortality and clinical expressions of patients with chronic obstructive pulmonary disease: the TORCH experience. Am J Respir Crit Care Med. 2011;183(3):317-322.

doi: https://doi.org/10.1164/rccm.201004-0665OC

32. Han MLK, Arteaga-Solis E, Blenis J, et al. Female sex and gender in lung/sleep health and disease: increased understanding of basic biological, pathophysiological, and behavioral mechanisms leading to better health for female patients with lung disease. Am J Respir Crit Care Med. 2018;198(7):850-858.

doi: https://doi.org/10.1164/rccm.201801-0168WS

33. Al-Lami RA, Urban RJ, Volpi E, Algburi AMA, Baillargeon J. Sex hormones and novel corona virus infectious disease (COVID-19). Mayo Clin Proc. 2020;95(8):1710-1714.

doi: https://doi.org/10.1016/j.mayocp.2020.05.013

34. Straub RH. The complex role of estrogens in inflammation. Endocr Rev. 2007;28(5):521-574.

doi: https://doi.org/10.1210/er.2007-0001

35. Channappanavar R, Fett C, Mack M, Ten Eyck PP, Meyerholz DK, Perlman S. Sex-based differences in susceptibility to severe acute respiratory syndrome coronavirus infection. J Immunol. 2017;198(10):4046-4053.

doi: https://doi.org/10.4049/jimmunol.1601896

36. Nguyen NT, Chinn J, Nahmias J, et al. Outcomes and mortality among adults hospitalized with COVID-19 at US medical centers. JAMA Netw Open. 2021;4(3):e210417.

doi: https://doi.org/10.1001/jamanetworkopen.2021.0417
37. Soriano JB, Polverino F, Cosio BG. What is early COPD and why is it important? Eur Respir J. 2018;52(6):1801448. doi: https://doi.org/10.1183/13993003.01448-2018

38. Schultze A, Walker AJ, MacKenna B, et al. Risk of COVID-19-related death among patients with chronic obstructive pulmonary disease or asthma prescribed inhaled corticosteroids: an observational cohort study using the OpenSAFELY platform. Lancet Respir Med. 2020;8(11):1106-1120. doi: https://doi.org/10.1016/S2213-2600(20)30415-X

39. Bauer CMT, Morissette MC, Stämpfli MR. The influence of cigarette smoking on viral infections: translating bench science to impact COPD pathogenesis and acute exacerbations of COPD clinically. Chest. 2013;143(1):196-206. doi: https://doi.org/10.1378/chest.12-0930

40. Leung JM, Niikura M, Yang CWT, Sin DD. COVID-19 and COPD. Eur Respir J. 2020;56(2):1-9.

doi: https://doi.org/10.1183/13993003.02108-2020

41. Polverino F. Cigarette smoking and COVID-19: a complex interaction. Am J Respir Crit Care Med. 2020;202(3):471-472. doi: https://doi.org/10.1164/rccm.202005-1646LE

42. Cai G, Bossé Y, Xiao F, Kheradmand F, Amos CI. Tobacco smoking increases the lung gene expression of ACE2, the receptor of SARSCoV-2. Am J Respir Crit Care Med. 2020;201(12):1557-1559. doi: https://doi.org/10.1164/rccm.202003-0693LE

43. Leung JM, Yang CX, Tam A, et al. ACE-2 expression in the small airway epithelia of smokers and COPD patients: implications for COVID-19. Eur Respir J. 2020;55(5):2000688. doi: https://doi.org/10.1183/13993003.00688-2020

44. Song J, Zeng M, Wang H, et al. Distinct effects of asthma and COPD comorbidity on disease expression and outcome in patients with COVID-19. Allergy Eur J Allergy Clin Immunol. 2020;76(2):483-496. doi: https://doi.org/10.1111/all.14517

45. Lindenauer PK, Dharmarajan K, Qin L, Lin Z, Gershon AS, Krumholz HM. Risk trajectories of readmission and death in the first year after hospitalization for chronic obstructive pulmonary disease. Am J Respir Crit Care Med. 2018;197(8):1009-1017. doi: https://doi.org/10.1164/rccm.201709-1852OC

46. Gupta S, Hayek SS, Wang W, et al. Factors associated with death in critically ill patients with coronavirus disease 2019 in the US. JAMA Intern Med. 2020;180(11):1436-1446.

doi: https://doi.org/10.1001/jamainternmed.2020.3596

47. Esposito AJ, Menon AA, Ghosh AJ, et al. Increased odds of death for patients with interstitial lung disease and COVID-19: a case-control study. Am J Respir Crit Care Med. 2020;202(12):1-15. doi: https://doi.org/10.1164/rccm.202006-2441LE

48. Gallay L, Uzunhan Y, Borie R, et al. Risk factors for mortality after COVID-19 in patients with preexisting interstitial lung disease. Am J Respir Crit Care Med. 2021;203(2):245-249. doi: https://doi.org/10.1164/rccm.202007-2638LE 
49. Prieto-Centurion V, Rolle AJ, Au DH, etal. Multicenter study comparing case definitions used to identify patients with chronic obstructive pulmonary disease. Am J Respir Crit Care Med. 2014;190(9):989-995. doi: https://doi.org/10.1164/rccm.201406-1166OC

50. Schnell K, Weiss CO, Lee T, et al. The prevalence of clinically-relevant comorbid conditions in patients with physician-diagnosed COPD: a cross-sectional study using data from NHANES 1999-2008. BMC Pulm Med. 2012;12(1):1-9.

doi: https://doi.org/10.1186/1471-2466-12-26 